I Universidade Federal de São Carlos (UFSCar), Departamento

de Ciências Sociais, São Carlos, SP, Brasil

lsr@ufscar.br.

Lidiane Soares Rodrigues'

\title{
OS SONHOS CENTRAIS DA PERIFERIA
}

Miceli, Sergio. (2018). Sonhos da periferia. Inteligência argentina e mecenato privado. São Paulo: Todavia.

O livro Sonhos da periferia. Inteligência argentina e mecenato privado é o condensado de 17 anos dedicados pelo sociólogo Sergio Miceli ao estudo da renovação literária argentina, entre as décadas de ig20 e i940. Os leitores que acompanharam sua produção a respeito do assunto talvez tenham notado que esse livro põe em relevo a Argentina, que comanda o prisma comparativista, numa equação inversa à dos trabalhos anteriores, nos quais a economia dos argumentos tendia a fazer do vizinho o contraponto ao Brasil.

"A vanguarda argentina na década de I920", primeiro capítulo, caracteriza dois modelos de viabilização material da produção literária: na Argentina, eles foram patrocinados pelo mecenato privado; no Brasil, dependeram do regime de cooptação estatal. Por isso, enquanto "o escritor vanguardista argentino é $[. .$.$] um jornalista em-$ pregado na equipe de redatores liderada por algum magnata da imprensa", e sua literatura, um dos "subprodutos de sua atividade regular" (p. 33); "o brasileiro é um letrado profissional nas centenas de horas vagas que lhe propiciam os afazeres bem remunerados no setor público" (p. 33). Os dois tipos de mecenato pontilham "universo temático", "gêneros literários" e "linguagens utilizadas para dar conta dos diagnósticos sorrateiros do mundo social engrendrados pelo tratamento ficcional" (p. 9I). O arranjo brasileiro, por exemplo, não daria origem a um projeto literário de "reter as feições mais extravagantes das estórias reelaboradas a partir das colunas diá- 
rias (produzidas para jornais)"(p. 28) como é o caso de Robert Arlt (I900I942). É que os brasileiros estavam então sob amparo do Estado, enquanto os argentinos se expunham aos efeitos da circulação ampliada de bens simbólicos.

O segundo capítulo, "A inteligência estrangeirada de SUR" elabora uma biografia coletiva dos patronos dessa revista, contemplando o conjunto de preferências literárias, estéticas, políticas. O propósito é nitidamente enunciado. Trata-se de superar a alternativa entre a denúncia do esnobismo de classe que mira Victoria Ocampo (I890-1979) e o extasiado enlevo pela "literatura imaculada" de Jorge Luis Borges (I 899-I986).

O terceiro capítulo, "Sexo, voz e abismo", é dedicado a Alfonsina Storni (I892-1938) e a Horacio Quiroga (I878I937), dois escritores rebaixados pela régua estética da vanguarda martinfierrista e da roda de Borges. Eles sobreviveram, a despeito disso, por meio do ganha-pão garantido pelo trabalho em jornais e revistas, destinados a uma clientela de preferências e de repertório opostos aos dos leitores de SUR. Os polos dominado e dominante das práticas literárias em questão revelam-se opostos e interdependentes.

Das numerosas soluções instigantes do livro - escrito em ritmo sincopado pelas justaposições léxicas desconcertantes, mesmo para os habituados ao vocabulário do sociólogo - mereceriam mais discussão do que permite o espaço de uma sumária notícia bibliográfica: as passagens luminosas de demonstração da apropriação que Bor- ges fez do cinema, assim como de seus arranjos formais e de conteúdo, comandados pela ânsia de adentrar com dignidade o panteão da "literatura universal”; a abordagem estruturante e relacional dos polos dominante (SUR) e dominado, este último figurado por Alfonsina e Quiroga, e, igualmente, a reconstituição da truncada parceria amorosa de ambos, desembocando na tocante análise de seus suicídios - momento de vibração sociológica ímpar no livro. Como o espaço de que disponho restringe as observações, reservo- o para uma questão decisiva que fez e faz girar os sonhos da(s) periferia(s). Refiro-me à posição que elas assumem nas barganhas assimétricas e bilaterais (importações e exportações) do espaço transnacional.

São fulcrais as relações dos argentinos com o modernismo da antiga metrópole espanhola e sua integração no continente, por meio do idioma. Elas tornam inteligível a "posição de força" ocupada pela Argentina "no âmbito do intercâmbio cultural entre a Espanha e os demais centros latinoamericanos de fala espanhola": enquanto o espanhol facultava o "acesso a mercados estrangeiros, a começar pelas praças latino-americanas, o idioma brasileiro estava confinado ao território nacional" (p. Io). Logo, não fosse essa integração, simultaneamente econômica e linguística, o mecenato da literatura argentina seria outro - e, também, o contraste com o Brasil. Não por acaso, essa dimensão estruturante é refratada nos móveis das tomadas de posição simbólica entre os escritores argentinos. Ela opu- 
nha Borges, e sua proposta de proteger o idioma dos argentinos das expressões populares oriundas dos imigrantes, a Arlt e seu projeto do lunfardo, linguagem flexível disposta a jogar com a expressividade dos estrangeirismos (p. 28).

Portanto, em "A vanguarda argentina na década de I920", as relações internacionais econômicas e simbólicas atrelam-se ao comparativismo entre Argentina e Brasil. Já no segundo capítulo, vinculam-se à problemática de longa duração na tradição do ensaísmo latino-americano e brasileiro: a definição de uma identidade própria numa relação agonística de denegação e importação das matrizes culturais dos países dominantes no espaço transnacional do intercâmbio econômico e político.

A revista SUR ambicionava alçar-se ao cosmopolitismo, defendendo uma concepção de autonomia da atividade intelectual, cujo conteúdo era o expurgo da fuligem filistina e de assuntos acalorados da política. Essa veleidade elegia dois periódicos europeus como métrica para a proeza, tendo neles as fontes de importação e de divulgação de ensaístas, filósofos e artistas do Velho Mundo: a Revista de Occidente (espanhola) e a Nouvelle Revue Française. A eclosão da Guerra Civil Espanhola (julho de I936) e a ocupação alemã da França (maio de I940) durante a Segunda Guerra Mundial (I939-I945) são marcos factuais da incontornável obrigação de a revista argentina tomar posição no espectro político, atitude da qual desviava esmeradamente. A elasticidade das alianças heterogêneas com segmentos do espectro ideológico alcançou seu limite. A lógica resultante das múltiplas oposições entre as frações dirigentes em afanosa disputa pela direção ideológica do setor cultivado da elite argentina impactou os significados assumidos nacionalmente pelos bens simbólicos internacionais. De um lado, a hierarquia eclesiástica, cujos interesses institucionais levavam ao apoio incondicional do franquismo, na expectativa de vantagens similares àquelas observadas após o triunfo de Mussolini na Itália; de outro lado, a inteligência laica de SUR, sustentando tanto quanto possível, em nome da autonomia da cultura, a terceira via, de não adesão dos católicos aos extremismos temporais. Essa conduta será acusada, ora de esquerdista, ora de ingenuidade útil aos soviéticos e aos comunistas, tanto pelo periódico Criterio - concorrente de SUR e porta-voz das tomadas de posição eclesiástica católica - quanto por Ortega e Gasset (XXX), em passagem por Buenos Aires, e por Pierre Drieu la Rochelle (I893-I945), parceiro amoroso de Victoria Ocampo que veio a aderir à extrema direita e se tornar líder dos colaboracionistas franceses.

O enguiço ideológico exprime a impossível manutenção da postura da "arte pela arte" num cenário de extrema polarização ideológica em que a terceira via é empurrada pela extrema direita para a esquerda; e, por esta, àquela. A análise da visita realizada por Jacques Maritain e da questão judaica, opondo a inteligência laica de SUR à eclesiástica, arremata a seção mais sinuosa do capítulo "Política 
(guerra)". O sistema político e cultural nacional de destino dos bens simbólicos mediava o rearranjo dos termos importados segundo sua lógica conflitiva própria, irredutível e sem contrapartida mecânica no campo nacional que os exportou. Ademais, a guerra revelava a dimensão onírica da autoimagem do país sustentada pela elite cultural - se Paris estava ocupada, e Londres, bombardeada, Buenos Aires ia "em busca de novas parcerias", por exemplo, um vizinho com o qual se assemelhava mais do que outrora pudera admitir - o Brasil (p. 65).

Ninguém ignora que a questão do intercâmbio transnacional em destaque já ocupara o sociólogo. Em A noite da madrinha (Miceli, 2005), livro originalmente escrito como dissertação de mestrado, discutiu longamente as condições de apropriação da teoria de Pierre Bourdieu (que, ainda em gestação, pressupunha muito fortemente a existência do sistema de ensino francês) para o exame da sociedade brasileira. Em seguida, no estudo sobre os anatolianos, o galicismo dos escritores foi mobilizado como uma variável na construção do quadro das determinantes sociológicas. A questão jamais desapareceu de trabalhos posteriores, sendo mais saliente nos estudos do livro Nacional estrangeiro (Miceli, 2003).

Tampouco se poderia ignorar o fato de que, entre as décadas de i 970 e 2000, o ensaio que tratou do mesmo problema e que fez convergirem ensaístas e cientistas sociais brasileiros, em prós ou contras, alardeantes ou aquietados, foi As ideias fora do lugar, de Roberto Schwarz (1977). Como é sabido, a orien- tação teórica deste último - marxista de matriz lukacsiana, e, posteriormente, adorniana - não é a mesma de Sergio Miceli. Decerto a diferença dificulta o reconhecimento do parentesco que sugiro, posto que a organização social do trabalho intelectual cinde os grupos segundo filiações teóricas exclusivas (isto é, em regra, caso se pertença a uma, ignora-se a outra). Sem suprimir as diferenças entre ambos, do ponto de vista de uma sociologia histórica da cultura, o liame entre Sonhos da periferia e As ideias fora do lugar parece-me mais importante do que essa distância. Sugiro-o não por desdém à coerência e à discussão teórica. Explico.

As problemáticas às quais se retorna com sistematicidade não planejada, não necessariamente explícita, tampouco alardeada, exprimem de modo cabal a configuração de uma tradição intelectual. E é esse o caso que, a rigor, remontaria ao século XIX. Há parentesco entre o trato do "nacional por subtração" e do "nacional estrangeiro", para evocar dois títulos expressivos da atenção que Roberto Schwarz e Sergio Miceli dedicaram à herança colonial, à posição dos países periféricos independentes, aos enguiços e às múltiplas formas pelas quais a importação material e simbólica neles se processa, assim como à ancoragem nacional dos usos sociais e políticos dos bens e dos circuitos transnacionais e às aventuras das experiências que ambicionaram estabelecer práticas que alçassem acima da contingência política. Elas foram e ainda são estruturantes do campo cultural e científico dos países em questão - ou, 
dito de modo singelo, de nosso próprio destino como cientistas sociais Se esta sugestão suscitar reflexões e outras leituras, contrariadas ou simpáticas, penso que terei prestado o serviço cabível a uma resenha.

Recebida em 25/4/20I8 Aprovada em $3 / 5 / 20$ I 8

\section{REFERÊNCIAS BIBLIOGRÁFICAS}

Miceli, Sergio. (2005) [1972]. A noite da madrinha: e outros ensaios sobre o éter nacional. São Paulo: Companhia das Letras.

Miceli, Sergio. (2003). Nacional estrangeiro: história social e cultural do modernismo artístico em São Paulo. São Paulo: Companhia das Letras.

Schwarz, Roberto. (2000) [1972]. As ideias fora do lugar. In: Ao vencedor as batatas. São Paulo: Duas Cidades/Ed. 34.

Lidiane Soares Rodrigues é historiadora, formada pela Universidade de São Paulo, e professora do Departamento de Ciências Sociais da Universidade Federal de São Carlos (UFSCar). 